\title{
Cyclopropane fatty acyl synthase in Sinorhizobium meliloti
}

\author{
Libia Saborido Basconcillo, ${ }^{1}$ Rahat Zaheer, ${ }^{2}$ Turlough M. Finan ${ }^{2}$ \\ and Brian E. McCarry ${ }^{1}$ \\ ${ }^{1}$ Department of Chemistry, McMaster University, Hamilton, Ontario L8S 4L8, Canada \\ ${ }^{2}$ Center for Environmental Genomics, Department of Biology, McMaster University, Hamilton, \\ Ontario L8S 4L8, Canada
}

Correspondence

Brian E. McCarry

mccarry@mcmaster.ca

Received 23 July 2008

Revised 13 October 2008

Accepted 23 October 2008
Cyclopropane fatty acyl synthases (CFA synthases) are enzymes that catalyse the addition of a methylene group across cis double bonds of monounsaturated fatty acyl chains in lipids. We have investigated the function of two putative genes, cfa1 and cfa2, proposed to code for CFA synthases in Sinorhizobium meliloti. Total fatty acid composition and fatty acid distributions within lipid classes for wild-type and cfa1 and cfa2 mutant strains grown under $\mathrm{P}_{\mathrm{i}}$ starvation and in acidic culture conditions were obtained by GC/MS and by infusion ESI/MS/MS, respectively. For wildtype cells and the cfa1 mutant, total cyclopropane fatty acids (CFAs) increased by $10 \%$ and $15 \%$ under $\mathrm{P}_{\mathrm{i}}$ starvation and acidic conditions, respectively; whereas in the cfa2 mutant, CFAs were less than $0.1 \%$ of wild-type under both growth conditions. Reporter gene fusion experiments revealed that cfa1 and cfa2 were expressed at similar levels in free-living cells. Thus under the conditions we examined, cfa2 was required for the cyclopropanation of lipids in S. meliloti whereas the role of cfa 1 remains to be determined. Analysis of intact lipids revealed that cyclopropanation occurred on cis-11-octadecenoic acid located in either the sn-1 or the sn-2 position in phospholipids and that cyclopropanation in the $s n-2$ position occurred to a greater extent in phosphatidylcholines and sulfoquinovosyldiacylglycerols under acidic conditions than under $\mathrm{P}_{\mathrm{i}}$ starvation. The cfa2 gene was also required for cyclopropanation of non-phosphoruscontaining lipids. Principal components analysis revealed no differences in the cyclopropanation of four lipid classes. We concluded that cyclopropanation occurred independently of the polar head group. Neither cfa1 nor cfa2 was required for symbiotic nitrogen fixation.

\section{INTRODUCTION}

The soil bacterium Sinorhizobium meliloti infects the roots of Medicago sativa (alfalfa), forming nodules and establishing a beneficial symbiotic relationship in which the bacteria convert atmospheric nitrogen into a usable source of nitrogen for the plants (Garg \& Geetanjali, 2007). In the last two decades, extensive research has been conducted to understand the biochemistry and genetics of nitrogenfixing bacteria and their symbiosis with leguminous plants,

\footnotetext{
Abbreviations: CFA, cyclopropane fatty acid/acyl; DMPE, dimethylphosphatidylethanolamine; FAME, fatty acid methyl ester; MMPE, monomethylphosphatidylethanolamine; PC, phosphatidylcholine; PCA, principal components analysis; PE, phosphatidylethanolamine; PG, phosphatidylglycerol; SL, sulfoquinovosyldiacylglycerol; TMHS, 1,2diacylglyceryl-3-O-4'-(N,N,N-trimethyl)-homoserine. Relative positions of fatty acyl chains in lipids are represented by the fatty acid in the $s n-1$ position first followed by the fatty acid in the $s n-2$ position, separated by / as recommended by LIPID MAPS (http://www.lipidmaps. org/).

A supplementary table and figure are available with the online version of this paper.
}

given the importance of this process for sustainable agriculture (Cowie et al., 2006; Galibert et al., 2001; MacLean et al., 2007; Weidner et al., 2003). Soil bacteria encounter numerous adverse conditions in the environment, including increased soil salinity, acidic $\mathrm{pH}$ conditions and limited inorganic phosphate $\left(\mathrm{P}_{\mathrm{i}}\right)$ (Cheng et al., 2005; Garau et al., 2005; Ibragimova et al., 2006).

Phospholipids constitute up to $95 \%$ of S. meliloti lipids; they include phosphatidylcholines (PCs), monomethylphosphatidylethanolamines (MMPEs), phosphatidylethanolamines (PEs), dimethylphosphatidylethanolamines (DMPEs), phosphatidylglycerols (PGs) and cardiolipins (Geiger et al., 1999). Minor lipid classes (5\%) include ornithine lipids (OLs) and sulfoquinovosyldiacylglycerols (SLs). Under $\mathrm{P}_{\mathrm{i}}$-limiting conditions, S. meliloti partially substitutes membrane phospholipids with non-phosphorus-containing lipids, which can represent up to $70 \%$ of total lipids; these lipids include 1,2-diacylglyceryl-3-O$4^{\prime}$-( $N, N, N$-trimethyl)-homoserine lipids (TMHSs), SLs and OLs (Lopez-Lara et al., 2005). Recently, we showed for the first time that the percentage composition of 
cyclopropane fatty acids (CFAs) increased twofold under $\mathrm{P}_{\mathrm{i}}$ starvation conditions (Saborido Basconcillo \& McCarry, 2008). Two CFAs, cis-9,10-methylene hexadecanoic acid $[17: 0$ cyclo $(9,10)]$ and cis-11,12-methylene octadecanoic acid $[19: 0$ cyclo $(11,12)]$ and their biochemical precursors, cis-9-hexadecenoic acid [16:1(9)] and cis-11-octadecenoic acid [18:1(11)], have been identified in S. meliloti (Jarvis \& Tighe, 1994; Saborido Basconcillo \& McCarry, 2008). Cyclopropane fatty acyl synthases (CFA synthases) are enzymes that catalyse the addition of a methylene group from $S$-adenosylmethionine across cis double bonds of monounsaturated fatty acyl chains in phospholipids (Grogan \& Cronan, 1997). Cyclopropanation is a postsynthetic modification of phospholipids which reaches a maximum during the stationary growth phase (Grogan \& Cronan, 1997). While CFA synthase in Escherichai coli has been well studied (Courtois et al., 2004; Courtois \& Ploux, 2005; Wang et al., 1992), there appear to have been no studies as yet in S. meliloti. Two putative CFA synthases (SMc00358 and SMc02645) have been annotated as cfa1 and $c f a 2$ genes in $S$. meliloti but no genetic or metabolite analyses have been conducted to support these functional assignments. Here we report what we believe to be the first efforts in this area.

While the biological roles of CFAs in bacteria are not completely understood (Cronan, 2002), it has been demonstrated that cyclopropane-containing lipids protect bacteria from adverse conditions such as acidity (Ballen et al., 1998; Brown et al., 1997; Chang \& Cronan, 1999; Kim et al., 2005), freeze-drying (Munoz-Rojas et al., 2006), desiccation (Boumahdi et al., 2001) and exposure to pollutants (Fang et al., 2007; Mrozik et al., 2005, 2006). There is some debate as to whether an increase in cyclopropane content of bacterial membranes leads to a decrease in membrane fluidity (Loffhagen et al., 2007; Munoz-Rojas et al., 2006). Furthermore, CFAs are involved in the pathogenesis of Mycobacterium tuberculosis (Glickman et al., 2000; Rao et al., 2005) and have antifungal activity in the antagonistic fluorescent pseudomonads (Ayyadurai et al., 2007), making CFAs targets for the development of new drugs for the treatment of antibiotic-resistant strains of $M$. tuberculosis (Bhatt et al., 2007; Guianvarc'h et al., 2006; Sekanka et al., 2007). Since CFAs are important in bacteria-host interactions for some pathogens, we have examined their possible role in $S$. meliloti during the alfalfa root-nodulation symbiosis.

Typically, CFA synthase studies have involved analysis of total fatty acids by gas chromatography coupled to mass spectrometry (GC/MS) or fatty acid analysis of lipid classes isolated using thin-layer chromatography (TLC) (Correa et al., 1999; Grogan \& Cronan, 1997). However, intact lipids can be analysed directly by the infusion of crude extracts without the need for chromatography, using a combination of tandem mass spectrometric techniques (ESI/MS/MS); this approach is known as 'shotgun lipidomics' (Han \& Gross, 2003, 2005a, b). In this work, we used a shotgun lipidomics strategy to determine fatty acid distributions within five lipid classes (phospholipids and non-phosphorus-containing lipids). Principal components analysis was used to identify trends in the fatty acid distributions of lipid classes. MS/MS experiments were used to determine fatty acid compositions in lipids and their relative positions in lipids ( $s n-1$ vs $s n-2)$, which provided insights into the selectivity of CFA synthases. Total fatty acids were analysed as fatty acid methyl esters (FAMEs) by GC/MS using a micro-scale method which was developed to assure good recoveries of CFAs (Saborido Basconcillo \& McCarry, 2008).

The objectives of this work were: (1) to study and compare the effects of $P_{i}$ starvation and acidic conditions on lipid cyclopropanation in S. meliloti; (2) to determine whether the putative $c f a 1$ and $c f a 2$ genes encoded CFA synthases; (3) to determine substrate selectivity of CFA synthases in $S$. meliloti such as preference towards certain lipid classes; and (4) to determine whether CFA synthases exhibited a preference for monounsaturated fatty acyl chains located at either the $s n-1$ or $s n-2$ position in lipids.

\section{METHODS}

Bacterial strains and culture conditions. S. meliloti $\mathrm{RmP} 110$ is a pst $C^{+}$derivative of strain 1021 and thus has a wild-type Pho regulon phenotype (Yuan et al., 2006a). For $\mathrm{P}_{\mathrm{i}}$-limitation experiments, S. meliloti RmP110 cultures were grown in MOPS-buffered minimal medium (Bardin et al., 1996) with added $\mathrm{Co}^{2+}\left(10 \mathrm{ng} \mathrm{CoCl} \mathrm{ml}^{-1}\right)$, containing glucose $(15 \mathrm{mM})$ as the carbon source, in the presence of $2 \mathrm{mM} \mathrm{P}_{\mathrm{i}}$ or in the absence of added $\mathrm{P}_{\mathrm{i}}$. S. meliloti cells grown overnight in LBmc broth [Luria-Bertani (LB) broth containing $2.5 \mathrm{mM} \mathrm{CaCl}_{2}$ and $\left.2.5 \mathrm{mM} \mathrm{MgSO}_{4}\right]$ were washed with MOPSbuffered minimal medium ( 2 and $0 \mathrm{mM} \mathrm{P}_{\mathrm{i}}$ ), subcultured in this medium and grown for $36-40 \mathrm{~h}$ at $30{ }^{\circ} \mathrm{C}$ with shaking. Cultures used in the $\mathrm{pH}$ study were initially grown overnight in LBmc, washed with $0.85 \% \mathrm{NaCl}$ and subcultured in $\mathrm{M} 9$ minimal medium containing glucose $(15 \mathrm{mM})$, at $\mathrm{pH} 7.0$ and $\mathrm{pH} 5.5$ followed by an incubation of $36-40 \mathrm{~h}$ at $30{ }^{\circ} \mathrm{C}$ with shaking. In all cases, $500 \mathrm{ml}$ late-exponentialphase cultures $\left(\mathrm{OD}_{600} 0.6-0.9\right)$ were centrifuged at $5000 \mathrm{~g}$ for $20 \mathrm{~min}$, and the cell pellets were resuspended in $2.5 \mathrm{ml}$ medium and divided into $250 \mu \mathrm{l}$ aliquots in Eppendorf tubes. Each tube was centrifuged, the supernatant discarded and the wet pellets flash-frozen in liquid nitrogen and stored at $-80{ }^{\circ} \mathrm{C}$ until further use. The pellets (equivalent to $50 \mathrm{ml}$ of original culture) corresponded to $61.8 \pm 4.5 \mathrm{mg}$ wet weight with $2 \mathrm{mM} \mathrm{P}_{\mathrm{i}}(n=9)$ and $27.6 \pm 1.2 \mathrm{mg}$ with $0 \mathrm{mM} \mathrm{P}_{\mathrm{i}}(n=9)$ from MOPS media or $40.5 \pm 0.9 \mathrm{mg}$ with pH $7.0(n=9)$ and $37.0 \pm 2.0 \mathrm{mg}$ with pH $5.5(n=9)$ from M9 media. Lipid extracts prepared from cell pellets were used for fatty acid and intact lipid analyses.

Construction of S. meliloti cfa1 and cfa2 mutants. The S. meliloti $S M c 00358$ and $S M c 02645$ genes are annotated as $c f a 1$ and $c f a 2$, respectively (http://iant.toulouse.inra.fr/bacteria/annotation/cgi/rhime. cgi). The smc02644 gene, annotated as encoding a putative transcriptional accessory protein, is located on the same strand $204 \mathrm{nt}$ downstream of $c f a 2$, while smc00359, encoding a putative transmembrane protein putatively involved in electron transport, lies $275 \mathrm{nt}$ downstream of $c f a 1$. Since neither of the downstream genes appeared to be involved in cyclopropanation, we chose to investigate the role of the $c f a$ genes via the generation of $c f a$ insertion mutants. Single-crossover mutations in the $c f a$ genes were were constructed in the RmP110 background, as RmP110 has a 
wild-type Pho regulon phenotype and we wished to examine the effects of phosphate limitation on fatty acid cyclopropanation (Yuan et al., 2006b). Accordingly, $263 \mathrm{bp}$ and $271 \mathrm{bp}$ fragments were PCR amplified from within the $5^{\prime}$ regions of $c f a 1$ and $c f a 2$, respectively, using primers 5'-GCTCTAGAGCTATCGCATATGATGAAGTCGTTC-3' (XbaI site in bold) and $5^{\prime}$-TGCATGCATGTCACAACAGCTTCTGGATCGGATAGG-3' (NsiI site in bold) for $c f a 1$ and primers $5^{\prime}$-GCTCTAGAGCGGGATTGTTGAATCTACTTCGC-3' (XbaI site in bold) and 5'-CCATCGATGGTCACGCGACGATCGAATTGGTGAAGG-3' (ClaI site in bold) for $c f a 2$. Each of these fragments was cloned into plasmid pTH1360 (Yuan et al., 2006b) using appropriate restriction sites and the resultant plasmids from E. coli $\mathrm{DH} 5 \alpha$ were recombined into the S. meliloti RmP110 genome via triparental mating using MT616 as a helper strain (Finan et al., 1986). Single-crossover recombinants were selected on LB plates containing $200 \mu \mathrm{g}$ streptomycin $\mathrm{ml}^{-1}$ and $200 \mu \mathrm{g}$ neomycin $\mathrm{ml}^{-1}$. Representative colonies for each cointegrate mutant were streak-purified three times before further use. Plasmid pTH1360 contains a promoterless gusA gene downstream of the multiple cloning site for the generation of integrated transcriptional fusions. The structure of the recombinants was confirmed via the direct sequencing of purified and sheared genomic DNA preparations from transconjugant strains using a reverse primer from the $3^{\prime}$ region of gusA (5'-TTGGGGTTTCTACAGGACGTAAC- $3^{\prime}$ ). This primer could generate DNA sequence reading through the recombined region and into the $S$. meliloti genome, to confirm that the recombination occurred in the appropriate target sequences.

$\boldsymbol{\beta}$-Glucuronidase activity assays. The expression of the gus A gene, encoding $\beta$-glucuronidase, was measured using $S$. meliloti cultures grown in three different media: LBmc, MOPS-buffered minimal medium with 2 and $0 \mathrm{mM} \mathrm{P}_{\mathrm{i}}$, and $\mathrm{M} 9$ at $\mathrm{pH} 7.0$ and $\mathrm{pH}$ 5.5. To $100 \mu \mathrm{l}$ of cell culture, $400 \mu \mathrm{l}$ of GusA assay buffer [50 mM Na $3 \mathrm{PO}_{4}$ pH 7.4, 1 mM EDTA, $10 \mathrm{mM}$ DTT, $0.01 \%$ SDS and $0.44 \mathrm{mg} \mathrm{ml}^{-1}$ of substrate $p$-nitrophenyl- $\alpha$-D-glucopyranoside (pNPG) (Cowie et al., 2006)] was added, mixed well and incubated at room temperature until the development of yellow colour. The reaction was stopped by the addition of $500 \mu \mathrm{l}$ of a solution of $\mathrm{Na}_{2} \mathrm{CO}_{3}(1 \mathrm{M})$; mixtures were spun down for $2 \mathrm{~min}$ at $10000 \mathrm{~g}$ to remove cell debris and the supernatant was used to measure $A_{405}$. The enzyme activity values were expressed as Miller units [activity $=\left(A_{405} \times 1000\right) /[$ time $(\mathrm{min}) \times$ culture volume $\left.\left.(\mathrm{ml}) \times \mathrm{OD}_{600}\right]\right]$.

Fatty acid methyl ester (FAME) analysis. Fatty acids were analysed as their FAMEs by GC/MS. FAMEs were prepared from dried lipid extracts using a micro-scale one-vial method that employed sodium methoxide in methanol as described previously (Saborido Basconcillo \& McCarry, 2008).

Intact lipid analysis. Dried lipid extracts were prepared from wet cell pellets (50 ml culture) as described previously and dissolved in methanol/chloroform $(1: 1, \mathrm{v} / \mathrm{v}, 200 \mu \mathrm{l}$ ) (Saborido Basconcillo \& McCarry, 2008). Aliquots were diluted fivefold with methanol containing the internal standards 1,2-diheneicosanoylphosphatidylcholine $[\mathrm{PC}(21: 0 / 21: 0), 32 \mu \mathrm{mol}]$ and 1,2-dimyristoylphosphatidylethanolamine [PE(14:0/14:0), $28 \mu \mathrm{mol}]$; lithium chloride $(2.5 \mathrm{mM})$ was added only for analyses conducted in the positive ionization mode. For analysis in the negative ionization mode, aliquots were diluted fivefold with methanol containing 1,2-dilauroylphosphatidylglycerol $[\mathrm{PG}(12: 0 / 12: 0), 3 \mu \mathrm{mol}]$ as the internal standard. A Waters Quattro Ultima triple-quadrupole mass spectrometer equipped with a microelectrospray ion source and operating under the MassLynx software was used for the analysis of bacterial lipid extracts. The collision gas $\left(\mathrm{N}_{2}\right)$ pressure was $2 \times 10^{-3}$ bar and collision energies ranged between 25 and $50 \mathrm{eV}$. Bacterial lipid extracts were continuously infused at $1 \mu \mathrm{l} \mathrm{min}{ }^{-1}$ using a Harvard syringe pump in the positive ion mode with or without the addition of lithium chloride and in the negative ion mode (no $\mathrm{LiCl}$ added). PCs, PEs and TMHSs were analysed as $[\mathrm{M}+\mathrm{Li}]^{+}$ions using neutral loss scans of 189 (Hsu et al., 1998), 147 (Hsu \& Turk, 2000) and 74 mass units (authors' unpublished data) respectively. PGs and SLs were analysed as their $[\mathrm{M}-\mathrm{H}]^{-}$ions in the negative ionization mode using parent ion scans of $\mathrm{m} / \mathrm{z} 153$ (Griffiths, 2003; Han \& Gross, 2005a) and 225 ions (authors' unpublished data). In all experiments 100 spectra were averaged to afford a single mass spectrum. Peak areas obtained in each MS/MS spectrum were normalized to the area of the internal standard and used to obtain relative percentage compositions of molecular species in each lipid class.

Statistical analysis. Each bacterial culture was sampled then analysed in triplicate and all data are expressed as means. Wild-type cultures were grown in triplicate over a period of 1 year and analysed for fatty acid composition (See Supplementary Table S1, available with the online version of this paper). The analytical variabilities for fatty acid analyses were $\leqslant 20 \%$ for fatty acids with percentage composition exceeding $1 \%$. The biological variabilities were $\leqslant 20 \%$ over a 1 year period.

The SPSS statistical package, version 15.0, was used for statistical analysis. Student's $t$-test was used to evaluate the significance of the differences when only two groups were compared, whereas analysis of variance (ANOVA) was used for multiple group comparisons $(P \leqslant 0.05)$. Principal components analyses (PCAs) were performed using the Multivariate Analysis add-in for Excel, version 1.3 (Bristol Chemometrics).

\section{RESULTS}

\section{Total CFAs increase with $\mathbf{P}_{\mathrm{i}}$ starvation and acidity}

Table 1 presents the fatty acid composition data for $S$. meliloti wild-type and the $c f a 1$ and $c f a 2$ mutants under two stressed conditions: $\mathrm{P}_{\mathrm{i}}$ starvation compared to $2 \mathrm{mM} \mathrm{P}_{\mathrm{i}}$ and $\mathrm{pH} 5.5$ compared to $\mathrm{pH}$ 7.0. The levels of the major CFA [19:0cyclo $(11,12)]$ increased significantly under $\mathrm{P}_{\mathrm{i}}$ starvation conditions while the minor CFA $[17: 0$ cyclo $(9,10)]$ showed no change. Acidic conditions ( $\mathrm{pH}$ 5.5) caused significant increases in both CFAs in the wild-type ( $\mathrm{pH} 7.0$ ). The total increases in CFAs were $10 \%$ and $15 \%$ under $\mathrm{P}_{\mathrm{i}}$ starvation and acidic conditions, respectively.

Total fatty acid analyses were performed using a one-vial transmethylation method that employed sodium methoxide in methanol, the reagent of choice for the conversion of cyclopropane-containing lipids into their FAMEs (Grogan \& Cronan, 1997). While most studies of CFA synthases have employed basic hydrolysis followed by an acidcatalysed methylation with $\mathrm{HCl}$ to generate FAMEs from bacterial lipids (Boumahdi et al., 2001; Brown et al., 1997; Loffhagen et al., 2007; Mrozik et al., 2006; Munoz-Rojas et al., 2006), this methodology produced lower yields of CFAs from lipid extracts of $S$. meliloti compared to the sodium methoxide in methanol procedure (Saborido Basconcillo \& McCarry, 2008). CFAs $[17: 0 \operatorname{cyclo}(9,10)$ and 19:0 Cyclo(11,12)] were chromatographically resolved from their monounsaturated counterparts (17:1 and 19:1) (Saborido Basconcillo \& McCarry, 2008). 
Table 1. Relative percentage compositions of fatty acids in S. meliloti wild-type and cfa1 and cfa2 mutants in the presence of inorganic phosphate $\left(2 \mathrm{mM} \mathrm{P}_{\mathrm{i}}\right)$ relative to $\mathrm{P}_{\mathrm{i}}$ starvation, and at $\mathrm{pH} 7.0$ relative to $\mathrm{pH} 5.5$

ND, Not detected. Mean values in bold presented errors of less than $10 \%$.

\begin{tabular}{|c|c|c|c|c|c|c|c|c|c|c|c|c|}
\hline \multirow[t]{4}{*}{ Fatty acid } & \multicolumn{12}{|c|}{ Relative percentage composition of $S$. meliloti, mean values $(n=3)$} \\
\hline & \multicolumn{4}{|c|}{ Wild-type } & \multicolumn{4}{|c|}{ cfal mutant } & \multicolumn{4}{|c|}{$c f a 2$ mutant } \\
\hline & \multicolumn{2}{|c|}{$\mathbf{P}_{\mathbf{i}}$} & \multicolumn{2}{|c|}{$\mathrm{pH}$} & \multicolumn{2}{|c|}{$P_{i}$} & \multicolumn{2}{|c|}{$\mathrm{pH}$} & \multicolumn{2}{|c|}{$\mathbf{P}_{\mathrm{i}}$} & \multicolumn{2}{|c|}{$\mathrm{pH}$} \\
\hline & $2 \mathrm{mM}$ & $0 \mathrm{mM}$ & 7.0 & 5.5 & $2 \mathrm{mM}$ & $0 \mathrm{mM}$ & 7.0 & 5.5 & $2 \mathrm{mM}$ & $0 \mathrm{mM}$ & 7.0 & 5.5 \\
\hline $14: 0$ & 0.2 & 0.3 & 0.4 & 0.4 & 0.3 & 0.3 & 0.5 & 0.4 & 0.3 & 0.3 & 0.4 & 0.3 \\
\hline $16: 0$ & 13.0 & 11.9 & 12.5 & 12.1 & 14.4 & $10.9^{*}$ & 14.1 & 11.1 & $15.7 \dagger$ & $15.3 \ddagger$ & $17.9 \dagger$ & $12.4 \S$ \\
\hline $17: 0$ & 0.2 & 0.2 & 0.1 & $0.4 \|$ & 0.2 & 0.2 & 0.2 & 0.3 & 0.3 & 0.2 & 0.2 & 0.4 \\
\hline $18: 0$ & 3.6 & $1.8 \|$ & 4.0 & 2.7 & 3.1 & $1.3^{\star}$ & 4.8 & 2.6 & 4.9 & 2.4 & 8.1 & $2.9 \$$ \\
\hline $16: 1(9)$ & 1.2 & 1.4 & 0.6 & 0.7 & 1.5 & 1.3 & 1.1 & 0.9 & $3.3 \dagger$ & $3.6 \neq$ & $2.3 \dagger$ & 2.2 \\
\hline $18: 1(11)$ & 54.4 & $46.9 \|$ & 59.7 & $46.4 \|$ & 53.0 & $44.8^{\star}$ & 57.2 & $48.8^{\star}$ & $75.4 \dagger$ & $78.2 \ddagger$ & 71.0 & 81.8 § \\
\hline $17: 0 \operatorname{cyclo}(9,10)$ & 1.6 & 2.1 & 1.6 & 2.7\| & 1.9 & 2.4 & 1.6 & 2.3 & $\mathrm{ND} \dagger$ & $\mathrm{ND} \ddagger$ & $\mathrm{ND} \dagger$ & $\mathrm{ND} \ddagger$ \\
\hline $19: 0 \operatorname{cyclo}(11,12)$ & 25.8 & $35.5 \|$ & 20.9 & $34.6 \|$ & 25.6 & $38.7^{\star}$ & 20.6 & $33.6^{*}$ & $\mathrm{ND} \dagger$ & $\mathrm{ND} \ddagger$ & $\mathrm{ND} \dagger$ & $\mathrm{ND} \ddagger$ \\
\hline
\end{tabular}

${ }^{*} c f a 1$ mutant under stressed conditions $\left(0 \mathrm{mM} \mathrm{P} \mathrm{P}_{\mathrm{i}}\right.$ or $\left.\mathrm{pH} 5.5\right)$ is significantly different $(P \leqslant 0.05)$ from $c f a 1$ mutant under normal growth conditions (2 mM $\mathrm{P}_{\mathrm{i}}$ or $\mathrm{pH} 7.0$ ).

$\dagger$ Under normal growth conditions $\left(2 \mathrm{mM} \mathrm{P}_{\mathrm{i}}\right.$ or $\left.\mathrm{pH} 7.0\right)$, cfa2 mutant is significantly different from wild-type $(P \leqslant 0.05)$.

$\ddagger$ Under stressed conditions $(0 \mathrm{mM} \mathrm{P}$ or $\mathrm{pH} 5.5)$, cfa2 mutant is significantly different from wild-type $(P \leqslant 0.05)$.

$\$ c f a 2$ mutant under stressed conditions $(\mathrm{pH} 5.5)$ is significantly different $(P \leqslant 0.05)$ from $c f a 2$ mutant under normal growth conditions $(\mathrm{pH} 7.0)$. IIWild-type under stressed conditions $\left(0 \mathrm{mM} \mathrm{P} \mathrm{P}_{\mathrm{i}}\right.$ or $\left.\mathrm{pH} 5.5\right)$ is significantly different $(P \leqslant 0.05)$ from wild-type under normal growth conditions (2 mM $\mathrm{P}_{\mathrm{i}}$ or $\left.\mathrm{pH} 7.0\right)$.

\section{Cyclopropanation occurs in the sn-1 and sn-2 positions in lipids}

A shotgun lipidomics methodology was used to determine fatty acid distributions for seven lipid classes (PCs, PEs, MMPEs, PEs, PGs, SLs, TMHSs). In this paper, we focus on four lipid classes: PCs and PGs, which are the most abundant phospholipids in $S$. meliloti under normal growth conditions, and TMHSs and SLs, the major lipids under $P_{i}$ starvation conditions (Geiger et al., 1999). Lipid profiles of PCs and PGs are shown in Fig. 1 for the wildtype under normal growth conditions. The ions observed at $\mathrm{m} / \mathrm{z}$ 764.6, 766.7, 778.8, 780.8, 792.8, 806.8 and 820.8 corresponded to the $[\mathrm{M}+\mathrm{Li}]^{+}$adducts of PCs with fatty acid compositions of $34: 2,34: 1,35: 2,35: 1,36: 2,37: 2$ and $38: 2$, respectively (Fig. 1a). Similarly, the profiles of PGs revealed the presence of lipids with fatty acid compositions corresponding to $34: 2,34: 1,35: 2,35: 1$, $36: 2,37: 2$ and $38: 2$ (Fig. 1b). MS/MS experiments were conducted to identify which lipid species contained CFAs and the relative positions of these fatty acids ( $s n-1$ vs $s n-2)$ in lipids.

Collision-induced dissociation (CID) of $[\mathrm{M}+\mathrm{Li}]^{+}$adducts of PCs produces fragment ions due to the neutral losses of the lithiated polar head group $\left([\mathrm{M}+\mathrm{Li}-189]^{+}\right)$and the fatty acyl chains (Hsu et al., 1998; Hsu \& Turk, 2003). Characteristic fragment ions are observed at $\mathrm{m} / \mathrm{z}$ $[\mathrm{M}+\mathrm{Li}-59-\mathrm{RCOOH}]^{+},[\mathrm{M}+\mathrm{Li}-\mathrm{RCOOLi}]^{+}$and $[\mathrm{M}+$ $\mathrm{Li}-\mathrm{RCOOH}]^{+}$. Moreover, the $[\mathrm{M}+\mathrm{Li}-59-\mathrm{RCOOH}]^{+}$ ions produced by the loss of fatty acids from the $s n$ - 1 position are more intense than those produced by the loss of $s n$-2 fatty acids (Hsu \& Turk, 2003), which allowed the assignment of CFAs to the $s n-1$ or $s n-2$ positions. The PC$35: 2$, PC-35:1, PC-37:2 and PC- $38: 2$ species all contained CFAs as demonstrated by the presence of fragment ions at $m / z[\mathrm{M}+\mathrm{Li}-59-268.2]^{+}$or $[\mathrm{M}+\mathrm{Li}-9-296.3]^{+}$, corresponding to neutral losses of $\left[\mathrm{N}\left(\mathrm{CH}_{3}\right)_{3}+17: 0\right.$ cyclo] or $\left[\mathrm{N}\left(\mathrm{CH}_{3}\right)_{3}+19: 0\right.$ cyclo], respectively. The lipid PC-37:2, the most abundant cyclopropane-containing PC, was shown to have the 19:0cyclo and 18:1 fatty acids attached to the $s n-1$ and $s n-2$ positions, respectively (Fig. $2 \mathrm{a}$ ). The fragment ion at $\mathrm{m} / \mathrm{z} 465.3$ derived from the neutral loss of 18:1 was more intense than those corresponding to the loss of 19:0cyclo at $\mathrm{m} / z 451.4$ (Fig. 2a, inset); based on the work of Hsu \& Turk (2003) these data were interpreted as PC-37: 2 corresponding primarily to $\mathrm{PC}(18: 1 / 19: 0$ cyclo $)$. However, since these ions did not provide the $2: 1$ to $3: 1$ ratio of ion intensities reported by Hsu \& Turk (2003), PC$37: 2$ may contain some of the $\mathrm{PC}(19: 0$ cyclo/18:1) isomer.

Daughter ion spectra in the negative ionization mode of $[\mathrm{M}-\mathrm{H}]^{-}$ions of PG-33:1, PG-35:2, PG-35:1 and PG$37: 2$ showed the presence of CFAs indicated by carboxylate ions at $\mathrm{m} / z 267.2$ and 295.3. The relative positions $(s n-1$ vs $s n-2)$ of CFAs in PGs were determined because the [RCOO $^{-}$ions from fatty acids in the $s n-2$ position are more abundant than ions from the $s n-1$ position (Hsu \& 
(a) PCs
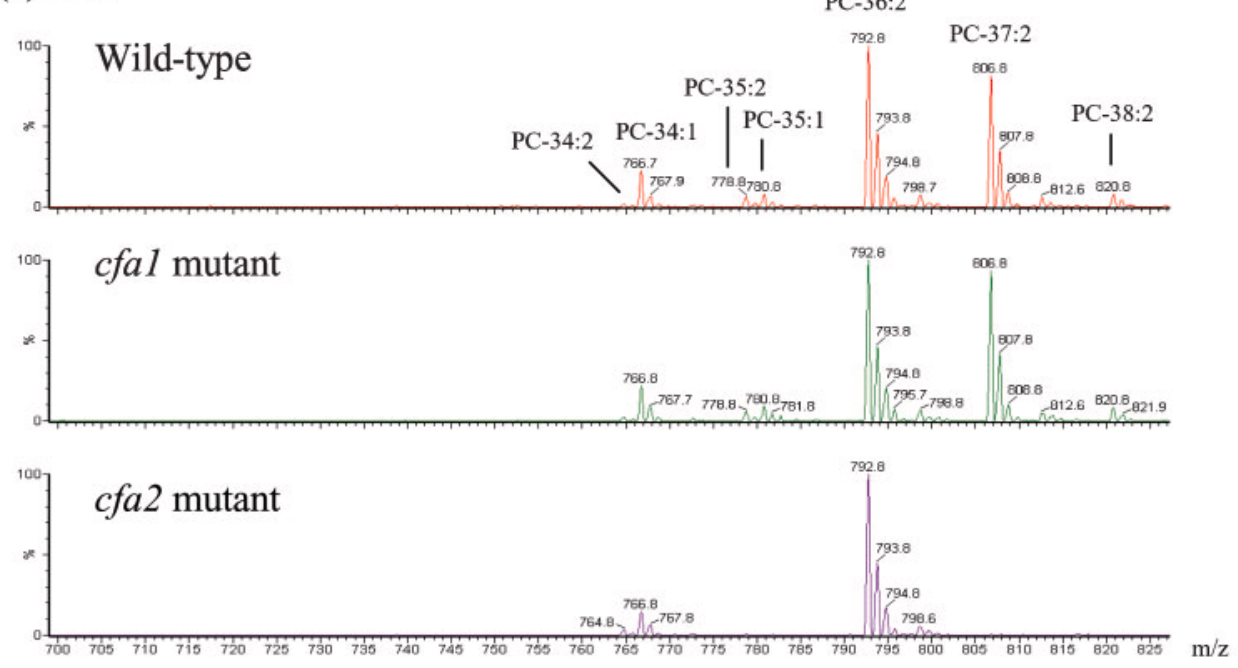

(b) PGs

(-) ESI/MS/MS
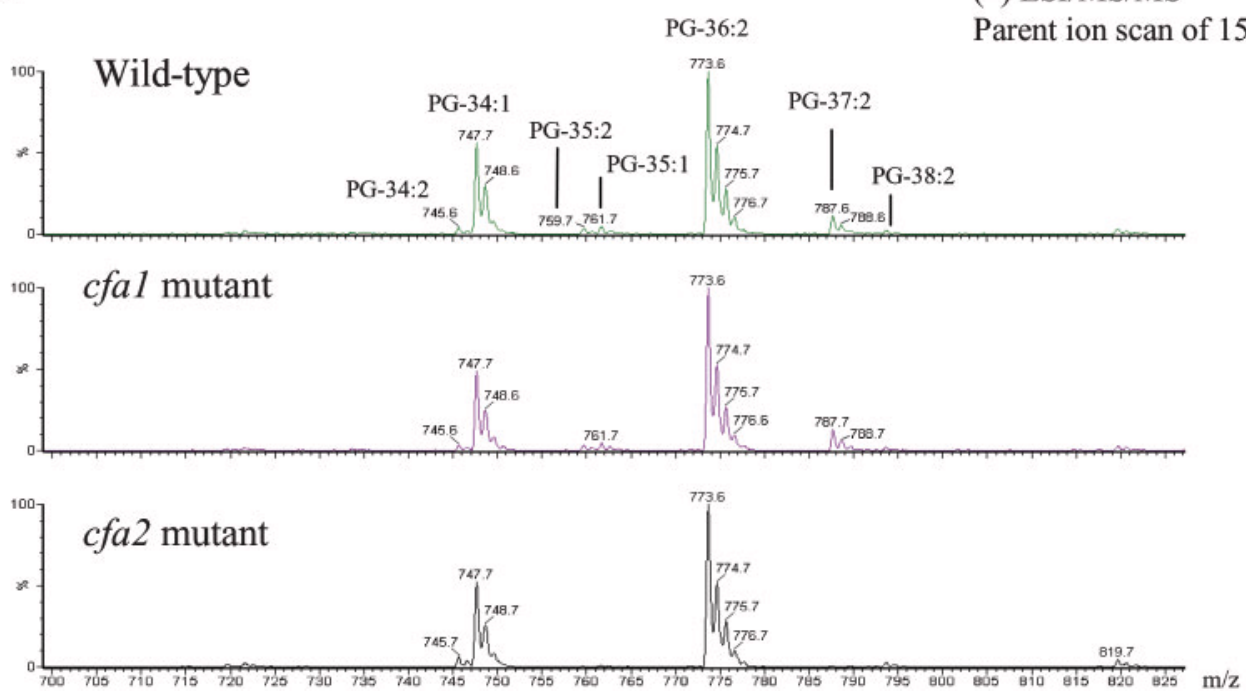

Fig. 1. $P C(a)$ and $P G(b)$ profiles of $S$. meliloti wild-type and the cfa1 and cfa2 mutants in the presence of $2 \mathrm{mM} P_{\mathrm{i}} \cdot \mathrm{NL}$, neutral loss scan.

Turk, 2001). The daughter ion spectrum of PG-37:2 clearly showed that this lipid corresponded to PG(19:0cyclo/18:1) (Fig. 2b).

The profiles for SLs and TMHSs, derived from wild-type and both knockout mutants with $\mathrm{P}_{\mathrm{i}}$ starvation, are shown in Fig. 3. The daughter ion spectra of $[\mathrm{M}-\mathrm{H}]^{-}$ions of SLs with fatty acid compositions of SL-35:2, SL-35:1, SL-37:2 and SL-38:2 showed that these lipids contained CFAs, as confirmed by the presence of [RCOO $^{-}$fragment ions in the MS/MS spectra at $m / z 267.2$ and 295.3 for $17: 0$ cyclo and 19:0cyclo, respectively. These spectra were interpreted as corresponding to lipids with fatty acid combinations of
SL(18:1/17:0cyclo), $\quad \operatorname{SL}(19: 0$ cyclo/16:0), $\quad \operatorname{SL}(18: 1 /$ 19:0cyclo) and SL(19:0cyclo/19:0cyclo), respectively. Lipid profiles of the TMHSs using neutral loss scans of 74 provided profiles similar to those observed for PCs (Fig. 1b) formed by TMHS-35:2, TMHS-35:1 and TMHS-37:2 lipids. The relative positions of fatty acids ( $s n-1$ vs $s n-2)$ in SLs and TMHSs could not be determined since the fragmentation mechanisms of these lipids have not been characterized due to the unavailability of analytical standards. However, cyclopropanation occurred in both the $s n-1$ and the $s n-2$ positions, demonstrated by the presence of $38: 2$ lipids. 

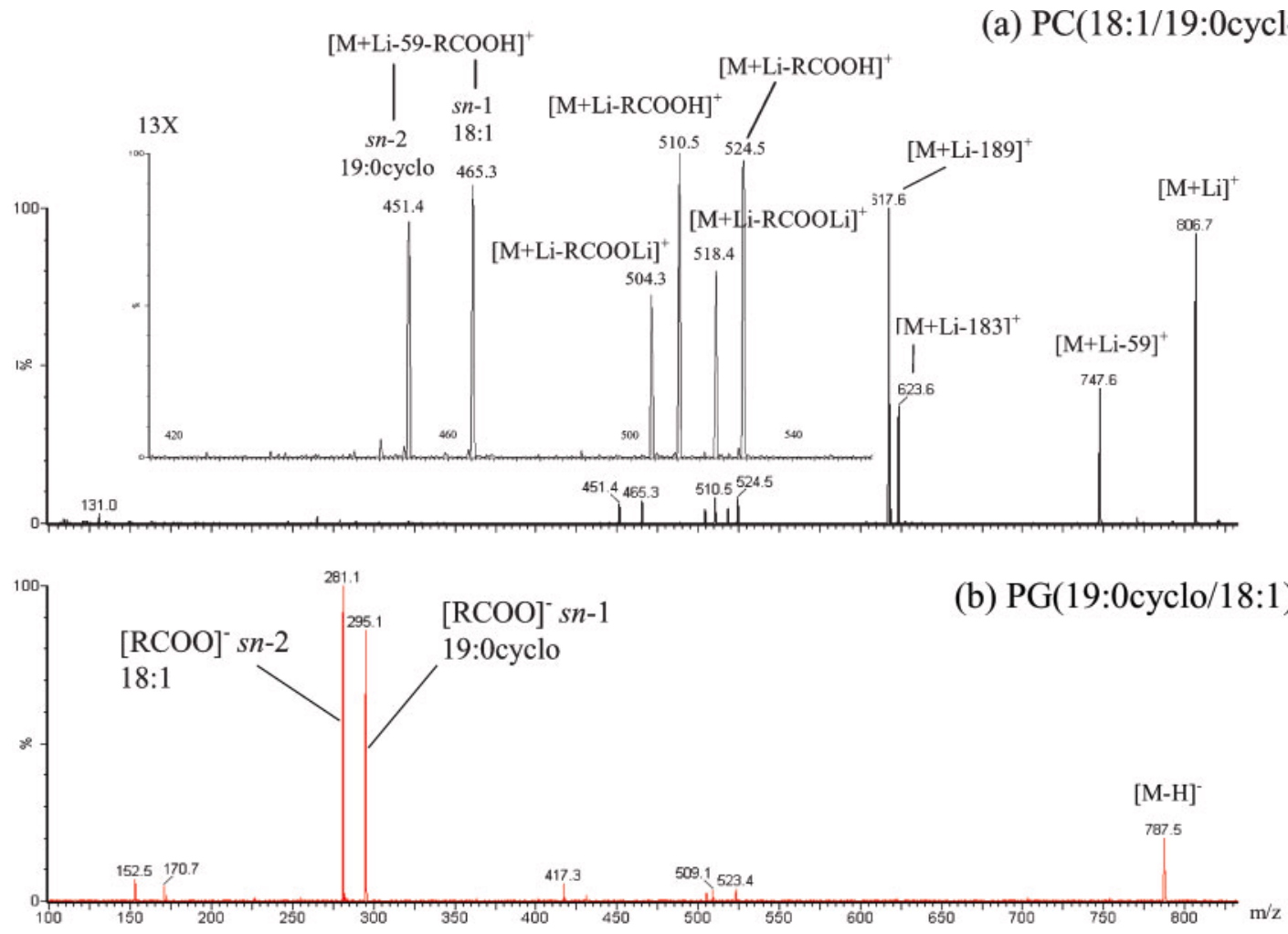

Fig. 2. Daughter ion spectra of $37: 2$ lipids of (a) PCs and (b) PGs in S. meliloti.

\section{Cyclopropanation of PCs and SLs occurs more extensively with acidity than with $P_{\mathbf{i}}$ starvation}

Tables 2 and 3 show relative percentage compositions in wild-type and $c f a$ mutant cells for PCs and PGs, respectively. Increased acidity and $\mathrm{P}_{\mathrm{i}}$ starvation caused an increase in cyclopropane-containing species $(35: 2,35: 1$, $37: 2,38: 2)$ in all lipid classes, while species that contained the biochemical precursors of CFAs (34:1 and 36:2) decreased significantly. PGs showed a similar trend; however, only PG-37:2 increased significantly while PG35:2 and PG-35:1 did not increase as observed for PCs (Table 3). PG-38:2 was a minor component and did not increase with $\mathrm{P}_{\mathrm{i}}$ starvation, while PC-38: 2 increased up to $4 \%$. PEs and SLs that contained CFAs also increased with $\mathrm{P}_{\mathrm{i}}$ starvation, reaching a maximum of $7 \%$ and $14 \%$, respectively, for $37: 2$ species (data not shown).

Under $\mathrm{P}_{\mathrm{i}}$ starvation, cyclopropanation increased in all lipid classes in general, but occurred to a larger extent in PCs and SLs than in PGs and PEs. Cyclopropanation was more pronounced under acidic conditions than under $\mathrm{P}_{\mathrm{i}}$ starvation; this phenomenon was manifested by further transformation of $37: 2$ lipids to $38: 2$ lipids in PCs (Table 2) instead of a build-up of $37: 2$ lipids as observed in PGs (Table 3). The same pattern as observed in PCs was present in SLs under acidic conditions, as SL-37:2 was further cyclopropanated to SL-38:2.

\section{cfa2 is required for the cyclopropanation of phospholipids and non-phosphorus-containing lipids in S. meliloti}

PGs and PCs containing CFAs (35:2, 35:1, 37:2, 38:2) decreased significantly $(87-100 \%)$ in $c f a 2$ mutant cells grown under $\mathrm{P}_{\mathrm{i}}$ starvation or in acidic conditions (Tables 2 and 3). In addition, cyclopropane-containing SLs and TMHSs were not detected in $c f a 2$ cultures (Fig. 3). Thus, $c f a 2$ is required for cyclopropanation of phospholipids and non-phosphorus-containing lipids. On the other hand, the lipid profiles of PCs, PGs, SLs and TMHSs in the $c f a 1$ mutant cells showed no significant differences compared to wild-type cells (Tables 2 and 3). Fatty acid composition data showed that CFAs were not detected in the cfa2 mutant, while the biochemical precursor of the major CFA (cis-11octadecenoic acid) exhibited a significant increase (Table 1). Fatty acid composition data of $c f a 1$ mutants were statistically identical to the wild-type under all conditions examined. It is noteworthy that CFAs in $c f a 2$ mutants were not detected by GC/MS analyses, while ESI/MS/MS techniques detected low levels $(<1 \%)$ of cyclopropane-containing lipids.

\section{Cyclopropanation in S. meliloti is independent of lipid class}

PCA was applied to the fatty acid distributions of lipid classes (PCs, PEs, PGs, SLs) in the wild-type and the $c f a 1$ 
(a) Wild-type
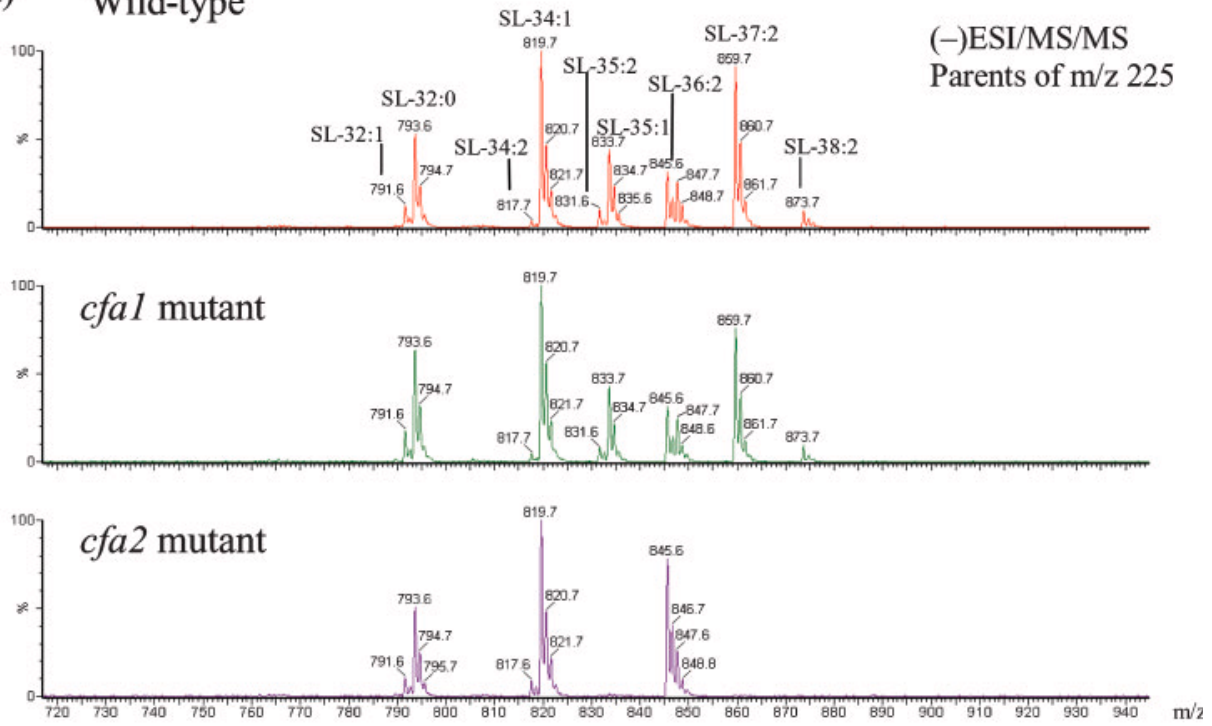

(b)
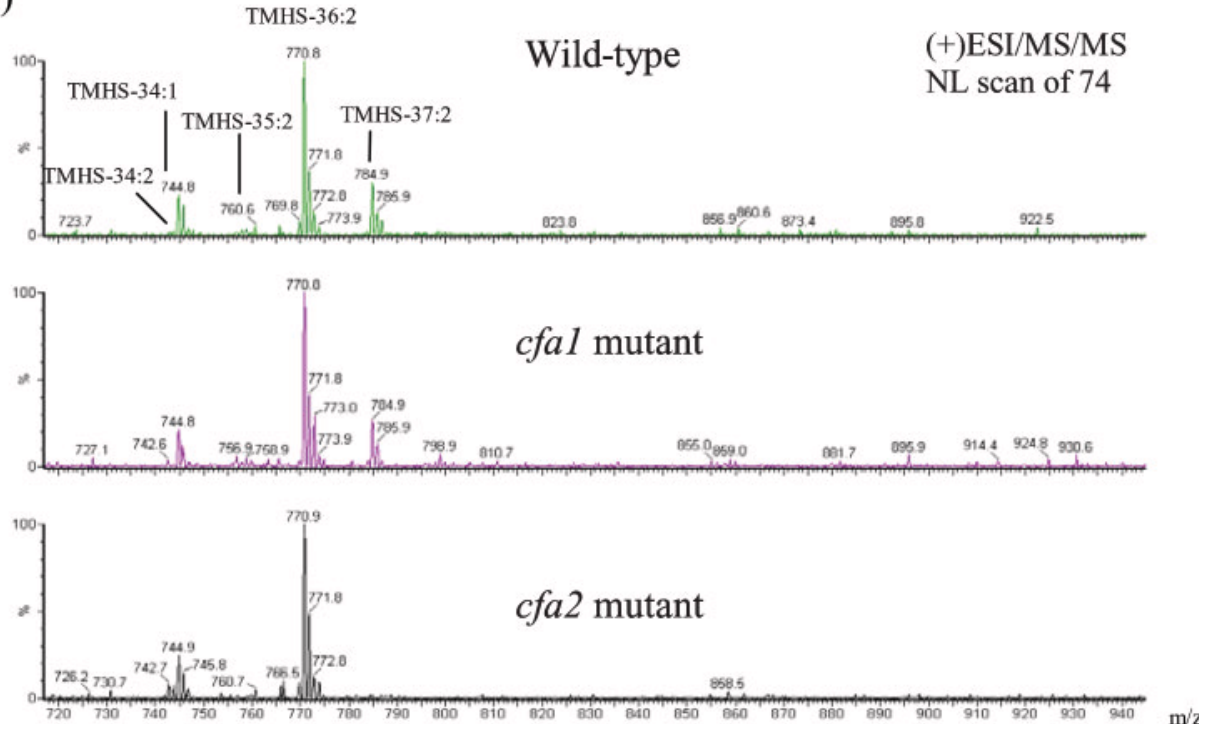

Fig. 3. Infusion electrospray mass spectra of non-polar extracts of $S$. meliloti wild-type and cfa1 and cfa2 mutants, showing the profiles of (a) SLs and (b) TMHSs with $\mathrm{P}_{\mathrm{i}}$ starvation. NL, neutral loss scan.

and $c f a 2$ mutants under all growth conditions in order to identify trends in the dataset (Fig. 4). In the scores plots (Fig. 4a, c), lipid classes are represented by different symbol shapes and the fatty acid compositions of individual lipids are represented by colours. PC1 accounts for $85 \%$ and PC2 for $13 \%$ of the variance in the dataset. Approximately half of the dataset clustered very tightly and therefore did not contribute to the differences observed in the loadings plots (Fig. 4b). The data points that did not cluster were grouped by colour (fatty acid composition) and not by symbol shape (lipid class). These data points corresponded to lipids with fatty acid compositions of $36: 2,34: 1,37: 2$ and
$38: 2$. Lipids with fatty acid compositions of $37: 2$ and $38: 2$ contained CFAs while lipids $36: 2$ and $34: 1$ contained the biochemical precursors of CFAs. Since data points clustered for certain fatty acid compositions (colours) and not for a particular lipid class (symbol shapes), the dataset was interpreted as indicating that cyclopropanation occurred independent of lipid classes. PC1 was correlated with percentage composition of lipids while PC2 represented the extent of cyclopropanation in lipids. In the loadings plots, samples with the highest percentage of cyclopropane-containing lipids were located in the top quadrant relative to PC2 (Fig. 4b), correspond- 
Table 2. Relative percentage composition of PCs in S. meliloti wild-type and cfa1 and cfa2 mutants with 2 mM $P_{i}$ relative to 0 mM $P_{i}$ and at $\mathrm{pH} 7.0$ relative to $\mathrm{pH} 5.5$

ND, Not detected. Mean values in bold presented errors of less than $10 \%$.

\begin{tabular}{|c|c|c|c|c|c|c|c|c|c|c|c|c|c|}
\hline \multirow[t]{4}{*}{ Lipid } & \multirow{4}{*}{$\begin{array}{l}\text { Fatty acids in lipids } \\
\qquad(s n-1 / s n-2) \#\end{array}$} & \multicolumn{12}{|c|}{ Relative percentage composition of phosphatidylcholines, mean values $(n=3)$} \\
\hline & & \multicolumn{4}{|c|}{ Wild-type } & \multicolumn{4}{|c|}{ cfa1 mutant } & \multicolumn{4}{|c|}{$c f a 2$ mutant } \\
\hline & & \multicolumn{2}{|c|}{$\mathbf{P}_{\mathbf{i}}$} & \multicolumn{2}{|c|}{$\mathrm{pH}$} & \multicolumn{2}{|c|}{$\mathbf{P}_{\mathbf{i}}$} & \multicolumn{2}{|c|}{$\mathrm{pH}$} & \multicolumn{2}{|c|}{$\mathbf{P}_{\mathbf{i}}$} & \multicolumn{2}{|c|}{$\mathrm{pH}$} \\
\hline & & $2 \mathrm{mM}$ & $0 \mathrm{mM}$ & 7.0 & 5.5 & $2 \mathrm{mM}$ & $0 \mathrm{mM}$ & 7.0 & 5.5 & $2 \mathrm{mM}$ & $0 \mathrm{mM}$ & 7.0 & 5.5 \\
\hline PC-34:2 & $16: 1 / 18: 1$ & 0.7 & 0.8 & 0.7 & 0.5 & 1.9 & 0.8 & 0.8 & 0.4 & $3.3^{*}$ & $3.6 \dagger$ & $5.0^{*}$ & $4.7 \dagger$ \\
\hline PC-34: 1 & $18: 1 / 16: 0$ & 9.1 & $6.5 \ddagger$ & 7.5 & 7.0 & 9.0 & $5.8 \S$ & 8.5 & $6.0 \$$ & 12.2 & $10.3 \dagger$ & 9.4 & $13.7+\|$ \\
\hline PC-35: 2 & $\begin{array}{c}18: 1 / 17: 0 \text { cyclo; } \\
16: 1-19: 0 \text { cyclo }\end{array}$ & 2.9 & 3.1 & 2.7 & 2.0 & 3.0 & 3.2 & 3.2 & 2.4 & 1.9 & 2.0 & $\mathrm{ND}^{*}$ & $\mathrm{ND} \dagger$ \\
\hline PC-35: 1 & $19: 0$ cyclo/16:0 & 3.5 & $4.9 \ddagger$ & 3.4 & $7.8 \ddagger$ & 4.2 & 4.6 & 3.8 & $7.3 \S$ & $1.4^{*}$ & $1.7 \dagger$ & $\mathrm{ND}^{*}$ & $\mathrm{ND} \dagger$ \\
\hline PC-36:2 & $18: 1 / 18: 1$ & 43.7 & $26.3 \ddagger$ & 35.4 & $19.4 \ddagger$ & 42.3 & $30.9 \S$ & 37.3 & $22.5 \S$ & $78.4^{*}$ & $79.5 \dagger$ & $85.6^{*}$ & $81.6 \dagger$ \\
\hline PC-37:2 & $19: 0$ cyclo/18: 1 & 36.2 & $48.3 \ddagger$ & 44.8 & 46.7 & 35.7 & $46.7 \S$ & 40.3 & $46.8 \S$ & $1.7^{\star}$ & $2.2 \dagger$ & $\mathrm{ND}^{*}$ & $\mathrm{ND} \dagger$ \\
\hline PC-38: 2 & 19:0cyclo/19:0cyclo & 3.9 & 10.1 ‡ & 5.6 & $16.5 \ddagger$ & 4.0 & $8.0 \$$ & 6.2 & $14.5 \S^{*}$ & $1.1^{*}$ & $0.8 \dagger$ & $\mathrm{ND}^{*}$ & $\mathrm{ND}^{\dagger}$ \\
\hline
\end{tabular}

\#When the assignment of fatty acids to the $s n-1$ and $s n-2$ positions in lipids was ambiguous, the fatty acids are separated by a hyphen instead of a forward slash.

${ }^{\star}$ Under normal growth conditions $\left(2 \mathrm{mM} \mathrm{P} \mathrm{P}_{\mathrm{i}}\right.$ or $\left.\mathrm{pH} 7.0\right)$, cfa2 mutant is significantly different from wild-type $(P \leqslant 0.05)$.

$\dagger$ Under stressed conditions $\left(0 \mathrm{mM} \mathrm{P}_{\mathrm{i}}\right.$ or $\left.\mathrm{pH} 5.5\right)$, cfa2 mutant is significantly different from wild-type $(P \leqslant 0.05)$.

$\ddagger$ Wild-type under stressed conditions $\left(0 \mathrm{mM} \mathrm{P} \mathrm{P}_{\mathrm{i}}\right.$ or $\left.\mathrm{pH} 5.5\right)$ is significantly different $(P \leqslant 0.05)$ from wild-type under normal growth conditions (2 $\mathrm{mM} \mathrm{P}_{\mathrm{i}}$ or $\mathrm{pH} 7.0$ ).

$\$ c f a 1$ mutant under stressed conditions $\left(0 \mathrm{mM} \mathrm{P}_{\mathrm{i}}\right.$ or $\left.\mathrm{pH} 5.5\right)$ is significantly different $(P \leqslant 0.05)$ from $c f a 1$ mutant under normal growth conditions (2 mM $\mathrm{P}_{\mathrm{i}}$ or $\mathrm{pH} 7.0$ ).

IIcfa2 mutant under stressed conditions $\left(0 \mathrm{mM} \mathrm{P} \mathrm{P}_{\mathrm{i}}\right.$ or $\left.\mathrm{pH} 5.5\right)$ is significantly different $(P \leqslant 0.05)$ from $c f a 2$ mutant under normal growth conditions (2 $\mathrm{mM} \mathrm{P}_{\mathrm{i}}$ or $\mathrm{pH} 7.0$ ).

ing to samples under acidic conditions (wild-type and $c f a 1$ mutant), while samples with the lowest content of cyclopropane-containing lipids were located at the bottom (cfa2 mutants).

Cyclopropanation of lipids was more accentuated with acidity than with $\mathrm{P}_{\mathrm{i}}$ starvation since samples at $\mathrm{pH} 5.5$ were preceded by samples at $0 \mathrm{mM} \mathrm{P}_{\mathrm{i}}$ along PC2. A third principal component (PC3) that contributed $2 \%$ of the variance differentiated samples at $\mathrm{pH} 5.5$ (wild-type and cfa1) given by an increase of $38: 2$ lipid species in PCs and SLs rather than an increase of $37: 2$ species (Fig. 4c, d). Two main conclusions can be made from PCA analysis: (i) acidity caused more extensive cyclopropanation of lipids than $\mathrm{P}_{\mathrm{i}}$ starvation and (ii) cyclopropanation of lipids did not occur preferentially for a given lipid class.

\section{Expression of the cfa genes and examination of the Cfa1 and Cfa2 proteins}

Since disruption of the $c f a 1$ and $c f a 2$ genes also created a transcriptional fusion to the uidA gene encoding $\beta$ glucuronidase (GusA), it was possible to measure promoter activities of those genes under various growth conditions. These data showed that $c f a 1$ and $c f a 2$ were expressed at similar levels in cells grown in M9 or MOPS-buffered minimal media at neutral $\mathrm{pH}$ or in rich medium LBmc (Fig. 5). However, $c f a 1$ and $c f a 2$ expression increased 3.2and 3.5-fold respectively, for cells grown in acidic conditions ( $\mathrm{pH} 5.5$ ) compared to cells grown under normal growth conditions ( $\mathrm{pH} 7.0$ ). All assays were conducted using cultures grown to the early stationary phase; assays performed on mid-exponential-phase cultures showed approximately half the activities for both $c f a 1$ and $c f a 2$ (data not shown), suggesting a twofold increase in promoter activities during stationary phase. To eliminate the possibility that the $c f a 1$ or $c f a 2$ mutations may influence their transcription, we also measured $c f a 1$ and $c f a 2$ transcripion using $c f a 1-$ and $c f a 2-g u s A$ transcriptional fusions (6448 and 869; Cowie et al., 2006) which do not disrupt the respective $c f a$ genes. Data from these strains were similar to those in Fig. 5; hence the disruption of these genes did not alter their transcription (data not shown).

\section{DISCUSSION}

To date, studies of CFA synthases have focused only on phospholipids, and the nature of the polar head group of phospholipids is thought to influence enzyme-substrate 
Table 3. Relative percentage compositions of PGs in S. meliloti wild-type and cfa1 and cfa2 mutants grown with 2 mM $P_{i}$ relative to $0 \mathrm{mM} \mathrm{P}$ and at $\mathrm{pH} 7.0$ relative to $\mathrm{pH} 5.5$

ND, Not detected. Mean values in bold presented errors of less than $10 \%$.

\begin{tabular}{|c|c|c|c|c|c|c|c|c|c|c|c|c|c|}
\hline \multirow[t]{4}{*}{ Lipid } & \multirow{4}{*}{$\begin{array}{l}\text { Fatty acids in lipids } \\
\qquad(s n-1 / s n-2) \#\end{array}$} & \multicolumn{12}{|c|}{ Relative percentage composition of phosphatidylglycerols, mean values $(n=3)$} \\
\hline & & \multicolumn{4}{|c|}{ Wild-type } & \multicolumn{4}{|c|}{$c f a 1$ mutant } & \multicolumn{4}{|c|}{$c f a 2$ mutant } \\
\hline & & \multicolumn{2}{|c|}{$\mathbf{P}_{\mathbf{i}}$} & \multicolumn{2}{|c|}{$\mathrm{pH}$} & \multicolumn{2}{|c|}{$\mathbf{P}_{\mathbf{i}}$} & \multicolumn{2}{|c|}{$\mathrm{pH}$} & \multicolumn{2}{|c|}{$\mathbf{P}_{\mathbf{i}}$} & \multicolumn{2}{|c|}{$\mathrm{pH}$} \\
\hline & & $2 \mathrm{mM}$ & $0 \mathrm{mM}$ & 7.0 & 5.5 & $2 \mathrm{mM}$ & $0 \mathrm{mM}$ & 7.0 & 5.5 & $2 \mathrm{mM}$ & $0 \mathrm{mM}$ & 7.0 & 5.5 \\
\hline PG-32:0 & $16: 0 / 16: 0$ & 1.6 & $\mathrm{ND}^{*}$ & 1.2 & 1.7 & 1.8 & $\mathrm{ND} \dagger$ & 1.3 & 1.4 & 2.0 & ND‡ & 1.5 & 1.9 \\
\hline PG-33: 1 & $16: 0 / 17: 0$ cyclo & ND & ND & 0.8 & 1.1 & ND & ND & 0.6 & $1.2 \dagger$ & ND & ND & NDS & 0.211 \\
\hline PG-33:0 & $17: 0-16: 0$ & $\mathrm{ND}$ & $\mathrm{ND}$ & 0.3 & 0.3 & $\mathrm{ND}$ & $\mathrm{ND}$ & 0.2 & 0.4 & ND & $\mathrm{ND}$ & $\mathrm{ND} \S$ & 0.1 \\
\hline PG-34:2 & $16: 1 / 18: 1$ & 1.9 & 1.5 & 1.5 & 1.0 & 2.2 & 1.5 & 1.4 & 1.2 & $3.9 \S$ & $5.4 \neq \|$ & $4.3 \S$ & $6.6 \neq \|$ \\
\hline PG-34: 1 & $18: 1 / 16: 0$ & 31.3 & $19.7^{\star}$ & 28.6 & $21.7^{\star}$ & 30.3 & 20.4 & 27.9 & $22.6 \dagger$ & 33.6 & $27.2 \neq \|$ & 29.0 & $27.2 \|$ \\
\hline PG-37:2 & $19: 0$ cyclo/18: 1 & 6.3 & $15.2^{*}$ & 9.9 & $24.7^{\star}$ & 6.3 & $12.0 \dagger$ & 9.4 & $20.8 \dagger$ & $0.3 \S$ & $\mathrm{ND} \|$ & $0.4 \S$ & $0.5 \|$ \\
\hline PG-38:2 & 19:0cyclo/19:0cyclo & ND & 0.7 & ND & ND & $\mathrm{ND}$ & $\mathrm{ND}$ & $\mathrm{ND}$ & ND & ND & ND & ND & ND \\
\hline
\end{tabular}

\#When the assignment of fatty acids to the $s n-1$ and $s n-2$ positions in lipids was ambiguous, the fatty acids were separated by a hyphen instead of a forward slash.

${ }^{*}$ Wild-type under stressed conditions $\left(0 \mathrm{mM} \mathrm{P} \mathrm{P}_{\mathrm{i}}\right.$ or $\left.\mathrm{pH} 5.5\right)$ is significantly different $(P \leqslant 0.05)$ from wild-type under normal growth conditions $\left(2 \mathrm{mM} \mathrm{P}_{\mathrm{i}}\right.$ or $\left.\mathrm{pH} 7.0\right)$.

$\dagger c f a 1$ mutant under stressed conditions $\left(0 \mathrm{mM} \mathrm{P}_{\mathrm{i}}\right.$ or $\left.\mathrm{pH} 5.5\right)$ is significantly different $(P \leqslant 0.05)$ from $c f a 1$ mutant under normal growth conditions (2 $\mathrm{mM} \mathrm{P}_{\mathrm{i}}$ or $\left.\mathrm{pH} 7.0\right)$.

$\ddagger c f a 2$ mutant under stressed conditions $\left(0 \mathrm{mM} \mathrm{P} \mathrm{P}_{\mathrm{i}}\right.$ or $\left.\mathrm{pH} 5.5\right)$ is significantly different $(P \leqslant 0.05)$ from $c f a 2$ mutant under normal growth conditions (2 $\mathrm{mM} \mathrm{P}_{\mathrm{i}}$ or $\left.\mathrm{pH} 7.0\right)$.

$\S$ Under normal growth conditions $\left(2 \mathrm{mM} \mathrm{P}_{\mathrm{i}}\right.$ or $\left.\mathrm{pH} 7.0\right), c f a 2$ mutant is significantly different from wild-type $(P \leqslant 0.05)$.

IIUnder stressed conditions $\left(0 \mathrm{mM} \mathrm{P}_{\mathrm{i}}\right.$ or $\left.\mathrm{pH} 5.5\right)$, cfa2 mutant is significantly different from wild-type $(P \leqslant 0.05)$.

interactions (Grogan \& Cronan, 1997). Here we investigated cyclopropanation of $S$. meliloti phospholipids (PCs, PGs, PEs) and two non-phosphorus-containing lipid classes (SLs, TMHSs). We showed that PCs and PGs with fatty acid compositions corresponding to $35: 2,35: 1,37: 2$ and $38: 2$ contained primarily cis-11,12-methyleneoctadecanoic acid. Lipids with these fatty acid compositions were also observed in non-phosphorus-containing lipid classes (SLs, TMHSs). The preferred substrates of most CFA synthases are lipids containing cis-9-hexadecenoic acid and not cis-11-octadecenoic acid (Grogan \& Cronan, 1997). However, since cis-11-octadecenoic acid is the major fatty acid in S. meliloti, it is not surprising that lipids containing this fatty acid were the principal CFA synthase substrate. MS/MS analyses of 37:2 lipids in S. meliloti showed that cis-11,12-methyleneoctadecanoic acid was mostly located in the $s n-2$ position in PCs while in PGs it was located at the $s n-1$ position. PC-37:2 most likely corresponds to a mixture of both isomers, where the $18: 1 / 19: 0$ cyclo isomer is more abundant. Therefore, in S. meliloti cyclopropana- tion of lipids occurred in both the $s n-1$ and $s n-2$ positions. CFA synthases have been reported to cyclopropanate preferentially fatty acyl chains located in the $s n-2$ position over $s n-1$ (Grogan \& Cronan, 1997).

The finding that cyclopropanation is drastically reduced in the $S$. meliloti cfa2 mutant, together with the sequence similarity of $\mathrm{Cfa} 2$ to known cyclopropane fatty acyl synthases, is strong evidence that $c f a 2$ encodes a cyclopropane fatty acyl synthase. As cyclopropanation of both phospholipids and non-phosphorus-containing lipids was absent in the cfa2 mutant, we infer that the nature of the polar head group had little effect on Cfa2-mediated cyclopropanation.

Both $\mathrm{P}_{\mathrm{i}}$ starvation and acidic conditions resulted in increased cyclopropanation of lipids $(10 \%$ and $15 \%$, respectively) in S. meliloti in all lipid classes examined. In general, higher rates of cyclopropanation in PCs and SLs were reflected by the transformation of $37: 2$ species to $38: 2$ species; in PGs and PEs conversion of $37: 2$ lipids to 


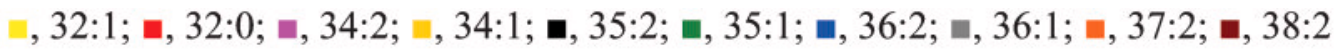
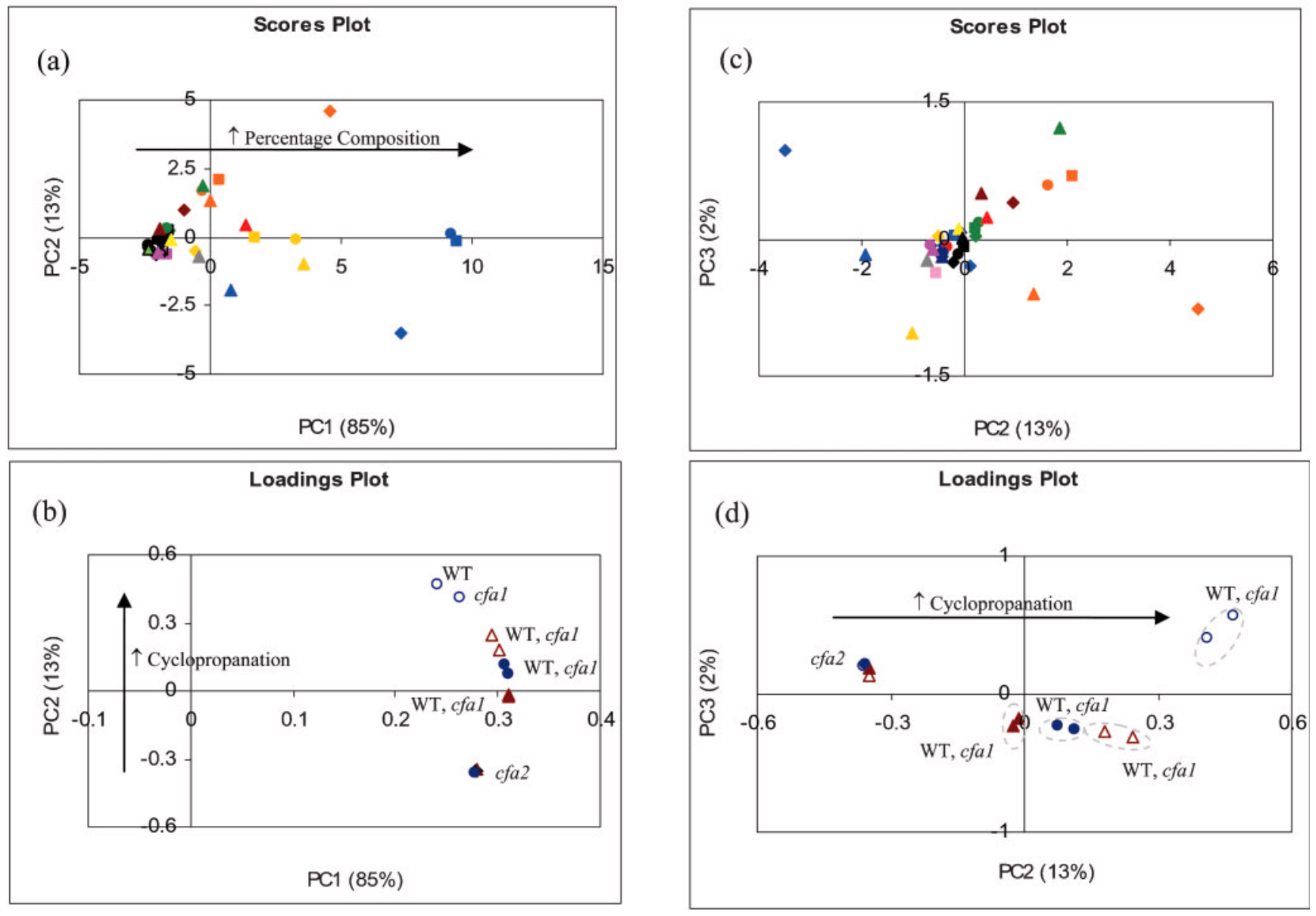

Fig. 4. PCA of fatty acid distributions in four lipid classes in S. meliloti wild-type and cfa1 and cfa2 mutants with $P_{i}$ starvation and acidic conditions. ( $(\mathrm{a}, \mathrm{c})$ In the scores plots, lipid classes are represented by different-shaped symbols ( $\bullet, \mathrm{PCs} ; \boldsymbol{\square}, \mathrm{PEs} ; \boldsymbol{\bullet}$, PGs; $\boldsymbol{\Delta}$, SLs). Lipid species are represented by colours (see key above figure). (b, d) In the loadings plots, the $P_{i}$ starvation study is represented by triangles and the acidity study by circles. Filled symbols represent control conditions $\left(2 \mathrm{mM} \mathrm{P}_{\mathrm{i}}, \mathrm{pH} 7.0\right)$ and hollow symbols represent stressed conditions $\left(0 \mathrm{mM} \mathrm{P} \mathrm{P}_{\mathrm{i}}, \mathrm{pH}\right.$ 5.5).

38:2 lipids was not observed. To our knowledge, $\mathrm{P}_{\mathrm{i}}$ starvation has not previously been linked to increased cyclopropanation; however, acidity has been shown to increase cyclopropanation of lipids by $17 \%$ in E. coli (Brown et al., 1997), and increased cfa transcription under acidic conditions has been reported for Lactococcus lactis (Budin-Verneuil et al., 2005). Recently, Rosenthal et al. (2008) reported an induction in transcription from the $E$. coli cfa promoter in response to acetate. They suggested that accumulation of protons that build up upon acid stress, and other small molecules such as acetate and glutamate that accumulate upon osmotic shock, can influence the transcription complexes at promoters, and as a result can alter the transcription profiles from those promoters. Since we observed increased transcription of both $c f a 1$ and $c f a 2$ in S. meliloti under acidic conditions but not under $\mathrm{P}_{\mathrm{i}}$ starvation conditions, the increased transcription would not seem to be part of a general stress response. Perhaps the increased cyclopropanation observed in $\mathrm{P}_{\mathrm{i}}$-starved cells is related to the shift in the lipid species composition that occurs in $\mathrm{P}_{\mathrm{i}}$-starved cells.

The role of Cfa1 in S. meliloti remains unclear, as it shares considerable sequence similarity with $\mathrm{Cfa} 2$ and other bacterial Cfa proteins. Since the $c f a 1$ and $c f a 2$ genes were transcribed at similar levels under all growth conditions (Fig. 5), and assuming each is translated, we infer that the Cfa1 protein either has a low activity $(<0.1 \%$ of Cfa2's activity based on fatty acid composition data) or has a different specificity from Cfa2. Pseudomonas putida also has two $c f a$-like genes and the gene designated $c f a B$ appears to encode the major CFA synthase activity, as a $c f a B$ mutant (containing only $c f a A$ ) produced less than $2 \%$ of the 17:cyclopropane produced by the wild-type strain (Munoz-Rojas et al., 2006). The S. meliloti Cfa1 or Cfa2 proteins showed $\sim 42 \%$ and $\sim 62 \%$ amino acid sequence 


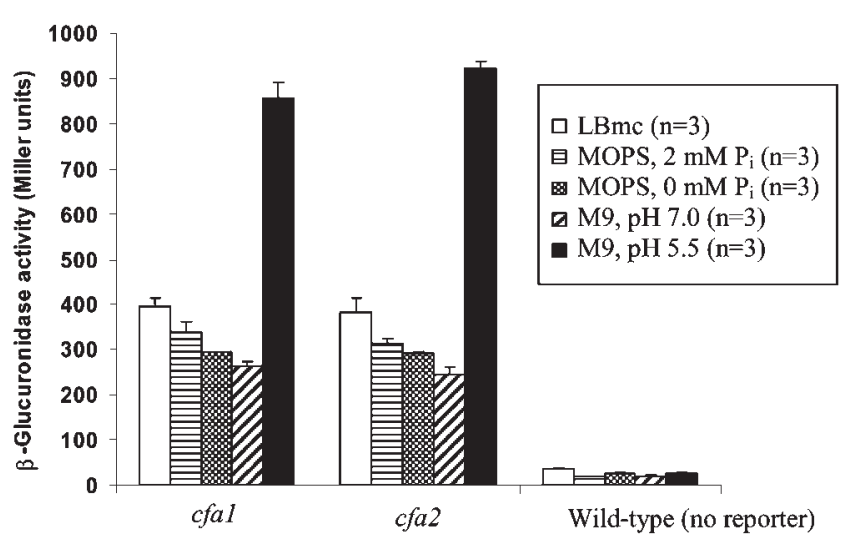

Fig. 5. Expression from cfa1 and cfa2 promoters in various growth media. Wild-type along with cfa1 and cfa2 mutant strains of $S$. meliloti were grown in LBmc rich medium, MOPS-buffered minimal medium with excess and without $\mathrm{P}_{\mathrm{i}}$ and $\mathrm{M} 9$ minimal medium at $\mathrm{pH} 7.0$ and $\mathrm{pH}$ 5.5. Means $\pm \mathrm{SD}, n=3$.

identities, respectively, to CFA synthase orthologues in Agrobacterium tumefaciens, Rhizobium etli and Rhizobium leguminosarum, each of which carries only one CFA synthase. Putative orthologues of Cfa have been found in all groups of bacteria; however, the presence of two or more CFA synthases has only been found in a few members of the proteobacteria, including $\alpha$ - (Sinorhizobium medicae, Mesorhizobium sp. BNC1, Acidiphilum cryptum, Xanthobacter autotrophicus and Roseovarius sp.), $\beta$ (Ralstonia solanacearum), $\gamma$ - (Serratia proteamaculans and Pseudomonas putida), and e-proteobacteria (Campylobacter jejuni), as well as among members of the Gram-positive Actinobacteria and Firmicutes (a few Mycobacterium species, Bacillus cereus, Clostridium beijerinckii and Lactobacillus reuteri).

The CFA synthase of E. coli has been well characterized (Huang et al., 2002; Wang et al., 1992) and the crystal structures of $M$. tuberculosis CFA synthases have been solved (Huang et al., 2002). In amino acid sequence alignments, Cfa1 shared $45 \%$ amino acid sequence identity with $\mathrm{Cfa} 2$, and both these proteins shared $35-40 \%$ amino acid identities with the Cfa proteins from E. coli, P. putida and M. tuberculosis proteins (Huang et al., 2002; MunozRojas et al., 2006; Wang et al., 1992). There were several regions that are conserved across all the Cfa proteins. These include amino acids 171-179 (E. coli Cfa numbering) corresponding to the motif (V/L)L(E/D)XGXGXG, which has been proposed to play a role in binding of the enzyme cofactor S-adenosylmethionine (Ingrosso et al., 1989). Similarly, residues $130-142$ and particularly C-139, which is thought to be involved in interactions with bicarbonate, are conserved (Courtois et al., 2004) (see Supplementary Fig. S1).

The biological functions of CFAs are not clear; however, they are involved in host-pathogen interactions in some bacteria such as M. tuberculosis (Glickman et al., 2000; Rao et al., 2005). In alfalfa plant nodulation assays, the $c f a 1$ and cfa2 mutants of $S$. meliloti did not show impaired nodulation or nitrogen fixation (data not shown). These results suggest that the CFAs of $S$. meliloti do not play a significant role in plant-bacteria interactions.

\section{ACKNOWLEDGEMENTS}

This work was supported by Genome Canada through the Ontario Genomics Institute, Toronto, ON, Canada. B. E. M. and T.M.F. are also grateful for NSERC support.

\section{REFERENCES}

Ayyadurai, N., Naik, P. R. \& Sakthivel, N. (2007). Functional characterization of antagonistic fluorescent pseudomonads associated with rhizospheric soil of rice (Oryza sativa L.). J Microbiol Biotechnol 17, 919-927.

Ballen, K. G., Graham, P. H., Jones, R. K. \& Bowers, J. H. (1998). Acidity and calcium interaction affecting cell envelope stability in Rhizobium. Can J Microbiol 44, 582-587.

Bardin, S., Dan, S., Osteras, M. \& Finan, T. M. (1996). A phosphate transport system is required for symbiotic nitrogen fixation by Rhizobium meliloti. J Bacteriol 178, 4540-4547.

Bhatt, A., Molle, V., Besra, G. S., Jacobs, W. R. \& Kremer, L. (2007). The Mycobacterium tuberculosis FAS-II condensing enzymes: their role in mycolic acid biosynthesis, acid-fastness, pathogenesis and in future drug development. Mol Microbiol 64, 1442-1454.

Boumahdi, M., Mary, P. \& Hornez, J. P. (2001). Changes in fatty acid composition and degree of unsaturation of (brady)rhizobia as a response to phases of growth, reduced water activities and mild desiccation. Antonie Van Leeuwenhoek 79, 73-79.

Brown, J. L., Ross, T., McMeekin, T. A. \& Nichols, P. D. (1997). Acid habituation of Escherichia coli and the potential role of cyclopropane fatty acids in low pH tolerance. Int J Food Microbiol 37, 163-173.

Budin-Verneuil, A., Maguin, E., Auffray, Y., Ehrlich, S. D. \& Pichereau, V. (2005). Transcriptional analysis of the cyclopropane fatty acid synthase gene of Lactococcus lactis MG1363 at low pH. FEMS Microbiol Lett 250, 189-194.

Chang, Y. Y. \& Cronan, J. E. (1999). Membrane cyclopropane fatty acid content is a major factor in acid resistance of Escherichia coli. Mol Microbiol 33, 249-259.

Cheng, Y., Waktin, E. L. J., Howieson, J. G. \& O'Hara, G. W. (2005). Root and root hair mechanisms that confer symbiotic competence for nodulation in acidic soils within Medicago species: a holistic model. Aust J Exp Agric 45, 231-240.

Correa, O. S., Rivas, E. A. \& Barneix, A. J. (1999). Cellular envelopes and tolerance to acid $\mathrm{pH}$ in Mesorhizobium loti. Curr Microbiol 38, 329-334.

Courtois, F. \& Ploux, O. (2005). Escherichia coli cyclopropane fatty acid synthase: is a bound bicarbonate ion the active-site base? Biochemistry 44, 13583-13590.

Courtois, F., Guerard, C., Thomas, X. \& Ploux, O. (2004). Escherichia coli cyclopropane fatty acid synthase. Eur J Biochem 271, 4769-4778.

Cowie, A., Cheng, J. J., Sibley, C. D., Fong, Y., Zaheer, R., Patten, C. L., Morton, R. M., Golding, G. B. \& Finan, T. M. (2006). An integrated approach to functional genomics: construction of a novel reporter gene fusion library for Sinorhizobium meliloti. Appl Environ Microbiol 72, 7156-7167. 
Cronan, J. E. (2002). Phospholipid modifications in bacteria. Curr Opin Microbiol 5, 202-205.

Fang, J. S., Lyon, D. Y., Wiesner, M. R., Dong, J. P. \& Alvarez, P. J. J. (2007). Effect of a fullerene water suspension on bacterial phospholipids and membrane phase behavior. Environ Sci Technol 41, 26362642.

Finan, T. M., Kunkel, B., Devos, G. F. \& Signer, E. R. (1986). Second symbiotic megaplasmid in Rhizobium meliloti carrying exopolysaccharide and thiamine synthesis genes. J Bacteriol 167, 66-72.

Galibert, F., Finan, T. M., Long, S. R., Puhler, A., Abola, P., Ampe, F., Barloy-Hubler, F., Barnett, M. J., Becker, A. \& other authors (2001). The composite genome of the legume symbiont Sinorhizobium meliloti. Science 293, 668-672.

Garau, G., Reeve, W. G., Brau, L., Deiana, P., Yates, R. J., James, D., Tiwari, R., O'Hara, G. W. \& Howieson, J. G. (2005). The symbiotic requirements of different Medicago spp. suggest the evolution of Sinorhizobium meliloti and S. medicae with hosts differentially adapted to soil pH. Plant Soil 276, 263-277.

Garg, N. \& Geetanjali (2007). Symbiotic nitrogen fixation in legume nodules: process and signaling. A review. Agron Sustain Dev 27, 59 68.

Geiger, O., Rohrs, V., Weissenmayer, B., Finan, T. M. \& ThomasOates, J. E. (1999). The regulator gene phoB mediates phosphate stress-controlled synthesis of the membrane lipid diacylglyceryl$\mathrm{N}, \mathrm{N}, \mathrm{N}$-trimethylhomoserine in Rhizobium (Sinorhizobium) meliloti. Mol Microbiol 32, 63-73.

Glickman, M. S., Cox, J. S. \& Jacobs, W. R. (2000). A novel mycolic acid cyclopropane synthetase is required for cording, persistence, and virulence of Mycobacterium tuberculosis. Mol Cell 5, 717-727.

Griffiths, W. J. (2003). Tandem mass spectrometry in the study of fatty acids, bile acids, and steroids. Mass Spectrom Rev 22, 81-152.

Grogan, D. W. \& Cronan, J. E. (1997). Cyclopropane ring formation in membrane lipids of bacteria. Microbiol Mol Biol Rev 61, 429-441.

Guianvarc'h, D., Drujon, T., Leang, T. E., Courtois, F. \& Ploux, O. (2006). Identification of new inhibitors of E. coli cyclopropane fatty acid synthase using a colorimetric assay. Biochim Biophys Acta 1764, $1381-1388$.

Han, X. L. \& Gross, R. W. (2003). Global analyses of cellular lipidomes directly from crude extracts of biological samples by ESI mass spectrometry: a bridge to lipidomics. J Lipid Res 44, 1071-1079.

Han, X. L. \& Gross, R. W. (2005a). Shotgun lipidomics: electrospray ionization mass spectrometric analysis and quantitation of cellular lipidomes directly from crude extracts of biological samples. Mass Spectrom Rev 24, 367-412.

Han, X. L. \& Gross, R. W. (2005b). Shotgun lipidomics: multidimensional MS analysis of cellular lipidomes. Expert Rev Proteomics 2, 253-264.

Hsu, F. F. \& Turk, J. (2000). Characterization of phosphatidylethanolamine as a lithiated adduct by triple quadrupole tandem mass spectrometry with electrospray ionization. J Mass Spectrom 35, 595-606.

Hsu, F. F. \& Turk, J. (2001). Studies on phosphatidylglycerol with triple quadrupole tandem mass spectrometry with electrospray ionization: fragmentation processes and structural characterization. J Am Soc Mass Spectrom 12, 1036-1043.

Hsu, F. F. \& Turk, J. (2003). Electrospray ionization/tandem quadrupole mass spectrometric studies on phosphatidylcholines: the fragmentation processes. J Am Soc Mass Spectrom 14, 352-363.

Hsu, F. F., Bohrer, A. \& Turk, J. (1998). Formation of lithiated adducts of glycerophosphocholine lipids facilitates their identification by electrospray ionization tandem mass spectrometry. J Am Soc Mass Spectrom 9, 516-526.
Huang, C. C., Smith, C. V., Glickman, M. S., Jacobs, W. R. \& Sacchettini, J. C. (2002). Crystal structures of mycolic acid cyclopropane synthases from Mycobacterium tuberculosis. J Biol Chem 277, 11559-11569.

Ibragimova, M. V., Rumyantseva, M. L., Onishchuk, O. P., Belova, V. S., Kurchak, O. N., Andronov, E. E., Dzyubenko, N. I. \& Simarov, B. V. (2006). Symbiosis between the root-nodule bacterium Sinorhizobium meliloti and alfalfa (Medicago sativa) under salinization conditions. Microbiology 75, 77-81.

Ingrosso, D., Fowler, A. V., Bleibaum, J. \& Clarke, S. (1989). Sequence of the D-aspartyl L-isoaspartyl protein methyltransferase from human-erythrocytes - common sequence motifs for protein, DNA, RNA, and small molecule $S$-adenosylmethionine-dependent methyltransferases. J Biol Chem 264, 20131-20139.

Jarvis, B. D. W. \& Tighe, S. W. (1994). Rapid identification of Rhizobium species based on cellular fatty-acid analysis. Plant Soil 161, 31-41.

Kim, B. H., Kim, S., Kim, H. G., Lee, J., Lee, I. S. \& Park, Y. K. (2005). The formation of cyclopropane fatty acids in Salmonella enterica serovar Typhimurium. Microbiology 151, 209-218.

Loffhagen, N., Hartig, C., Geyer, W., Voyevoda, M. \& Harms, H. (2007). Competition between cis, trans and cyclopropane fatty acid formation and its impact on membrane fluidity. Eng Life Sci 7, 67-74.

Lopez-Lara, I. M., Gao, J. L., Soto, M. J., Solares-Perez, A., Weissenmayer, B., Sohlenkamp, C., Verroios, G. P., ThomasOates, J. \& Geiger, O. (2005). Phosphorus-free membrane lipids of Sinorhizobium meliloti are not required for the symbiosis with alfalfa but contribute to increased cell yields under phosphorus-limiting conditions of growth. Mol Plant Microbe Interact 18, 973-982.

MacLean, A. M., Finan, T. M. \& Sadowsky, M. J. (2007). Genomes of the symbiotic nitrogen-fixing bacteria of legumes. Plant Physiol 144, 615-622.

Mrozik, A., Labuzek, S. \& Piotrowska-Seget, Z. (2005). Changes in fatty acid composition in Pseudomonas putida and Pseudomonas stutzeri during naphthalene degradation. Microbiol Res 160, 149-157.

Mrozik, A., Piotrowska-Seget, Z. \& Labuzek, S. (2006). Cellular fatty acid patterns in Pseudomonas sp. CF600 during catechol and phenol degradation in media supplemented with glucose as an additional carbon source. Ann Microbiol 56, 57-64.

Munoz-Rojas, J., Bernal, P., Duque, E., Godoy, P., Segura, A. \& Ramos, J. L. (2006). Involvement of cyclopropane fatty acids in the response of Pseudomonas putida KT2440 to freeze-drying. Appl Environ Microbiol 72, 472-477.

Rao, V., Fujiwara, N., Porcelli, S. A. \& Glickman, M. S. (2005). Mycobacterium tuberculosis controls host innate immune activation through cyclopropane modification of a glycolipid effector molecule. J Exp Med 201, 535-543.

Rosenthal, A. Z., Kim, Y. \& Gralla, J. D. (2008). Regulation of transcription by acetate in Escherichia coli: in vivo and in vitro comparisons. Mol Microbiol 68, 907-917.

Saborido Basconcillo, L. \& McCarry, B. E. (2008). Comparison of three GC/MS methodologies for the analysis of fatty acids in Sinorhizobium meliloti: development of a micro-scale, one-vial method. J Chromatogr B Analyt Technol Biomed Life Sci 871, 22-31.

Sekanka, G., Baird, M., Minnikin, D. \& Grooten, J. (2007). Mycolic acids for the control of tuberculosis. Expert Opin Ther Patents 17, 315-331.

Wang, A. Y., Grogan, D. W. \& Cronan, J. E., Jr (1992). Cyclopropane fatty-acid synthase of Escherichia coli: deduced amino-acid-sequence, purification, and studies of the enzyme active-site. Biochemistry 31, 11020-11028. 
Weidner, S., Puhler, A. \& Kuster, H. (2003). Genomics insights into symbiotic nitrogen fixation. Curr Opin Biotechnol 14, 200-205.

Yuan, Z. C., Zaheer, R. \& Finan, T. M. (2006a). Regulation and properties of PstSCAB, a high-affinity, high-velocity phosphate transport system of Sinorhizobium meliloti. J Bacteriol 188, 1089-1102.
Yuan, Z. C., Zaheer, R., Morton, R. \& Finan, T. M. (2006b). Genome prediction of PhoB regulated promoters in Sinorhizobium meliloti and twelve proteobacteria. Nucleic Acids Res 34, 2686-2697.

Edited by: W. Margolin 